$\stackrel{N / N}{=}$

Global burnals Inc.

औf
GLOBAL JOURNAL OF MEDICAL RESEARCH: B

PHARMA, DRUG DISCOVERY, TOXICOLOGY \& MEDICINE

Volume 20 Issue 4 Version 1.0 Year 2020

Type: Double Blind Peer Reviewed International Research Journal

Publisher: Global Journals Inc. (USA)

Online ISSN: 2249-4618 \& Print ISSN: 0975-5888

\title{
Evaluating Hydrocolloids of Sida Acuta as Sustained Release Matrix for Ibuprofen Tablet
}

\author{
By Akpabio E I, Uwah T O, Effiong D E \& Godwin J
}

University of Uyo

Abstract-Background and Objectives: Matrix tablet formulation for ibuprofen using natural hydrocolloids are a good alternative to conventional ibuprofen immediate-release tablet and would be a desired option as opposed to the use of synthetic polymer. This work was to prepare and evaluate sustained-release ibuprofen matrix tablets using Sida acuta gum. Guar gum is the reference natural polymer.

Materials and Methods: Sida gum was obtained from aqueous macerate of Sida acuta leaves then precipitated using acetone, whereas guar gum was purchased. Both gums were characterized for micromeritics, swelling properties, and hydration capacities. The granules of ibuprofen, using a gum for a separate batch, were prepared by wet granulation method. The matrix tablets were produced, physical properties determined, and dissolution studies carried out. The release kinetics values obtained were fit into equations for kinetic studies.

Keywords: Sida acuta gum, ibuprofen, sustained release, matrix tablet, guar gum.

GJMR-B Classification: NLMC Code: QV 745

Strictly as per the compliance and regulations of:

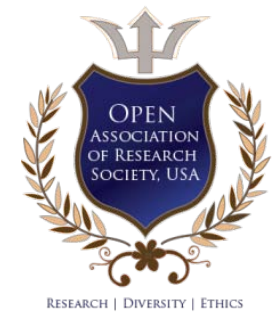

(C) 2020. Akpabio E I, Uwah T O, Effiong D E \& Godwin J. This is a research/review paper, distributed under the terms of the Creative Commons Attribution-Noncommercial 3.0 Unported License http://creativecommons.org/licenses/by-nc/3.0/), permitting all non-commercial use, distribution, and reproduction in any medium, provided the original work is properly cited. 


\title{
Evaluating Hydrocolloids of Sida Acuta as Sustained Release Matrix for Ibuprofen Tablet
}

\author{
Sustained Release Ibuprofen Tablet using Sida Acuta Gum
}

\author{
Akpabio $\mathrm{EI}^{\alpha}$, Uwah $\mathrm{TO}^{\sigma}$, Effiong $\mathrm{DE}{ }^{\rho} \&$ Godwin $\mathrm{J}^{\omega}$
}

\begin{abstract}
Background and Objectives: Matrix tablet formulation for ibuprofen using natural hydrocolloids are a good alternative to conventional ibuprofen immediate-release tablet and would be a desired option as opposed to the use of synthetic polymer. This work was to prepare and evaluate sustainedrelease ibuprofen matrix tablets using Sida acuta gum. Guar gum is the reference natural polymer.

Materials and Methods: Sida gum was obtained from aqueous macerate of Sida acuta leaves then precipitated using acetone, whereas guar gum was purchased. Both gums were characterized for micromeritics, swelling properties, and hydration capacities. The granules of ibuprofen, using a gum for a separate batch, were prepared by wet granulation method. The matrix tablets were produced, physical properties determined, and dissolution studies carried out. The release kinetics values obtained were fit into equations for kinetic studies.
\end{abstract}

Results: Ibuprofen granules using guar gum (G1) had a flow rate of $5.19 \mathrm{~g} / \mathrm{s}$ and particle density of $1.22 \mathrm{~g} / \mathrm{ml}$ while granules containing Sida acuta gum (G2) had a flow rate of $5.60 \mathrm{~g} / \mathrm{s}$, granule and particle density of $1.23 \mathrm{~g} / \mathrm{ml}$. Tablets for both batches complied with official standards in mechanical properties of friability and crushing strength. The release kinetics obtained from the in vitro dissolution study showed that Batch G1 released $94.55 \%$ of the ibuprofen while Batch G2 released $96.82 \%$ of it in the 8 hours. Both batches followed zero-order while the mechanism of release was nonFickian diffusion as the n-diffusion exponent was less than 0.5 for both batches. The t-test showed significant difference in the percentage of drug released by both batches of tablets $(\mathrm{P}<0.05)$.

Conclusion: Sida acuta gum was useful as the sustainedrelease delivery of ibuprofen as the matrix tablets gave out higher content of the therapeutic active ingredient hence could serve as a substitute for synthetic polymer in drug delivery.

Keywords: Sida acuta gum, ibuprofen, sustained release, matrix tablet, guar gum.

\footnotetext{
Corresponding Author $\alpha$ : Department of Pharmaceutics and Pharmaceutical Technology, Faculty of Pharmacy, University of Uyo, Nigeria.e-mail: pharmeka2000@yahoo.com

Author $\sigma \rho \omega$ : Department of Pharmaceutics and Pharmaceutical Technology, Faculty of Pharmacy, University of Uyo, Nigeria. e-mails: tymeuwah@yahoo.com, edaniel430@gmail.com, jjugat@gmail.com
}

\section{INTRODUCTION}

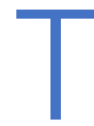
he non-invasiveness, convenience, and ease of administration that characterize the oral route make it the route of choice in drug use. Solid dosage form drug design and presentation (which uses the oral route) continues to be improved upon to achieve reduced dosage frequency, better patient compliance, and, more importantly, improved therapeutic efficacy. This tripartite intention of drug formulation is achievable when drugs are delivered at non-toxic steady state in the plasma or the tissue level despite changing the in-vivo environment ${ }^{1}$. Despite the many synonyms used to explain delivery strategies that maintain plasma steady-state, sustained-release (SR) is one of such nomenclatures that accurately describe drug delivery systems that help to achieve these intentions by continuously releasing the therapeutic actives over an extended period on single dosing, thereby maintaining a prolonged effect. Orals, injectibles, and topicals have been formulated as sustained delivery. Some approaches employed to arrive at sustained release include; encapsulation of slow-release granules, tableted slow release granules, drug complexation technique, coated tablets, ion activated system, and even the tablet matrix system ${ }^{1,2}$

In the matrix system, a therapeutic active is embedded throughout the polymer matrix of insoluble/hydrophilic substance. The release of the drug depends on drug dissolution within the polymer matrix and diffusing out through pores in the matrix. In some formulations, the matrix physically increases in size to form a gel as the drug dissolves in it, thus allowing the drug to exit through the gel's outer surface. Many naturally occurring polymers with unique, desirable drug release retarding characteristics are used in filling the roles of excipients for SR. For the matrix systems, polymers in use include starches, hydrocolloids and cellulose as well as their derivatives. The use of gums in dosage forms and in formulating sustained release are reported in the literature. ${ }^{3,4,5,6}$

Sida acuta (SA) is a weed of tropical, semi-avid, and occasionally sub-tropical and warmer temperate regions. It invades open woodlands, pastures, waterways (i.e., riparian vegetation) plantations, crops, and gardens. The whole plant, although smoked in 
Mexico as a substitute to Marihuana, is reported to being widely used as a traditional medicine in Columbia, especially as an external bath for snake bite ${ }^{7}$. The leaves of the plant are the source of the hydrocolloid used in this research work.

Ibuprofen is a non-steroidal anti-inflammatory drug (NSAID) used for treating pain, fever and inflammation. Some of the conditions it covers include dysmenorrhea, migraines, and rheumatoid arthritis. It has been used with some success for treating ankylosing spondylitis, gout, and psoriatic arthritis. It may reduce pain, fever, and inflammation of pericarditis. The need for managing recurrent chronic pain while overcoming frequency of administration, especially for drugs with short half-life, has necessitated the production of analgesics with sustained-release. One of such is the Neurofen ${ }^{\circledR} 300 \mathrm{mg}$ back pain capsules (an encapsulated slow-release pellet of ibuprofen). This work, therefore, was to design, formulate and evaluate sustained-release ibuprofen matrix tablets using Sida acuta hydrocolloid as the matrix former. Guar gum was used as a reference natural polymer.

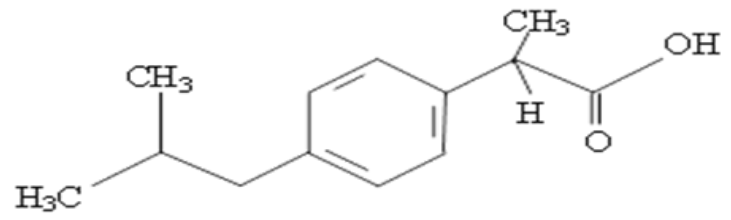

Fig. 1: Chemical structure of Ibuprofen

\section{il. Materials and Methods}

Ibuprofen hydrochloride, guar gum (Riedel De Haenac Seelze Hannover) and Microcrystalline cellulose (Guarajat Micro wax Limited, India) were obtained commercially whereas the Sida acuta gum was obtained locally from the leaves of the plant (from Faculty of Pharmacy farm, University of Uyo, Nigeria).

\section{a) Study area}

The study was carried out in the Undergraduate Pharmaceutics laboratory, instrument room for dosage form evaluation, and the tableting unit, all of the department of Pharmaceutics, Faculty of Pharmacy, University of Uyo, Nigeria from November 2018 - April 2019.

\section{b) Preparation of Sida acuta gum}

The leaves of the Sida acuta plant were collected, milled into small sizes, and weighed. The milled leaves were macerated in $7 \mathrm{~L}$ of hot water containing $0.1 \%$ of sodium metabisulphite for $24 \mathrm{~h}$. After that, the macerate was filtered. To the filtrate, an equal volume of acetone was added in order to precipitate the gum. The precipitate was further washed with acetone severally to remove the chlorophyll and then air-dried for $24 \mathrm{~h}$. The dried gum was weighed and evaluated.

\section{c) Evaluation of the gum}

The solubility, swelling index, water absorption index, $\mathrm{pH}$, and organoleptic features of the gum were determined as described in previous researches ${ }^{4,8}$

\section{d) Swelling Index}

About $1.0 \mathrm{~g}$ quantity of SA gum was weighed into a measuring cylinder, and the volume occupied noted. Distilled water $(10 \mathrm{~mL})$ was added to it, shaken vigorously, and allowed to stand for $24 \mathrm{~h}$. The supernatant was subsequently decanted but the volume of the sediment noted. The test was carried out in triplicate. The swelling index was calculated using the relation:

$$
S=\frac{\mathrm{V} 2}{\mathrm{~V} 1}
$$

Where $\mathrm{S}=$ Swelling index

$$
\mathrm{V} 1=\text { Gum volume before hydration }
$$$$
\text { V2 = Gum volume after hydration }
$$

This test was also carried out for the guar gum.

e) Solubility Test

The solubility of gum was evaluated three solvents: water, ethanol and acetone. A $1 \mathrm{~g}$ quantity of gum was weighed and placed in a clean test tube to which $10 \mathrm{~mL}$ of distilled water was added. The mixture was shaken vigorously and observed for formation of a homogenous phase. This same procedure was also carried out using the other solvents.

\section{f) Water Absorption Index}

A $1 \mathrm{~g}$ quantity of gum was weighed into a dish of known weight, and spread to cover the base of the dish. Water was filled in a bucket to a certain level to allow the petri dishes be placed, floating on the water in the bucket. The bucket was covered and allowed to stand for 24 hours, after which the petri dishes were, removed, wiped off, and re-weighed. This procedure was repeated for 48 hours, 72 hours and 96 hours, respectively. The percentage increase in weight, taken as the water absorption index was calculated. Determinations were done in triplicates.

\section{g) $\mathrm{pH}$ Test}

A $1 \% \mathrm{w} / \mathrm{v}$ dispersion of the gum in water was prepared and the $\mathrm{pH}$ determined using a bench-top $\mathrm{pH}$ meter (Thermo Scientific Orion Versa star). $\mathrm{pH}$ determinations were made in triplicate and the mean value, determined.

\section{h) Preparation of Granules}

Two batches of granules were prepared. A gum was used in each batch as the matrix-forming agent. The granules were prepared by the wet granulation technique. The ingredients were weighed accurately and properly mixed in a porcelain mortar. The weighed 
powdered mix was formed into a damp mass for granules production using 95\% ethanol. The wet mass was screened through a $2 \mathrm{~mm}$ stainless steel sieve and the resulting granules dried at $60^{\circ} \mathrm{C}$ in a hot air oven $(P$ Selecta, Spain) for 1 hour. The dried granules were further screened, using $1 \mathrm{~mm}$ stainless steel sieve, and stored for further evaluations.

Table 1: The composition of Ibuprofen-Matrix tablet

\begin{tabular}{lcc}
\hline Ingredients & G1 & G2 \\
\hline Ibuprofen (mg) & 200 & 200 \\
Guar gum (\%) & 20 & - \\
Sida acuta gum (\%) & - & 20 \\
Magnesium stearate (\%) & 1 & 1 \\
Talc (\%) & 1 & 1 \\
MCC q.S to & $400 \mathrm{mg}$ & $400 \mathrm{mg}$ \\
\hline
\end{tabular}

\section{i) Evaluation of Granules}

The flow rate, angle of repose, bulk density, tapped density, Hausner's quotient, and Carr's compressibility index were determined in line with methods described by Akpabioet al.,(2016) ${ }^{4}$ using $30 \mathrm{~g}$ of the granules.

\section{i. Granule density and Porosity}

The fluid displacement method was employed for determination. The weight of a $50 \mathrm{ml}$ pycnometer was determined and noted. After that, the pycnometer bottle was filled with xylene and the excess wiped off. The filled bottle was re-weighed and the difference between this new weight and the empty pycnometer bottle was calculated. A $0.5 \mathrm{~g}$ quantity of granules was transferred into the pycnometer bottle. The excess xylene displaced by the granules was wiped off, the bottle further re-weighed. The granule density was calculated using the equation below.

Granule density $\rho g=\frac{\rho(W s)}{W s-(W 2-W 1)}$

G Where

$\rho=$ density of xylene, $W s=$ weight of sample (granules),

$W_{2}=$ weight of pycnometer + xylene + sample

$W_{1}=$ weight of pycnometer + xylene

$$
\text { Granule porosity }(\varepsilon) \frac{100(1-\rho b)}{\rho g}
$$

Where

$\rho b=$ bulk density, and $\rho g=$ granule density

\section{j) Formulation of Ibuprofen matrix tablets}

The dried granules of ibuprofen were further sieved using a $0.25 \mathrm{~mm}$ stainless steel sieve to separate the fine granules from the coarse granules. The weight of the fine granules was determined and the percentage fines were calculated. The fine granules were mixed with magnesium stearate in a beaker and the coarse granules were also incorporated in the beaker and mixed properly. Talc was weighed and added to the mixture of granules and magnesium stearate, and the mixture was compressed at $25 \mathrm{KN}$ using a single punch tableting machine (Cadmach Machinery Co. Pvt Ltd, India).

\section{k) Evaluation of Physical Properties of the Tablets}

i. Tablet Diameter and Thickness

Ten tablets from each of the batches were selected at random and the diameter and thickness of each tablet was determined using the micrometer screw gauge. The average values of the parameters for each batch was then calculated.

\section{ii. Tablet Weight Uniformity}

Twenty tablets were randomly selected from each batch, weighed individually, and the average weight was determined using an electronic scale (Ohaus Corporation, Australia). The mean and percentage variation was calculated for each batch.

\section{iii. Tablet Hardness and Friability}

This was done using the hardness tester. Ten tablets were chosen at random from each batch. Each tablet was placed diametrically between the Monsanto hardness tester (Rolex, Chandigarh), and the force needed just to crush the tablet was noted. The mean of the hardness of each batch was determined. Another ten tablets from each batch were obtained dusted, weighed and placed in separate drums of a Roche friabilator (DT-2D). The tablets were tumbled at a speed of 25 revolutions per minute for 4 minutes. The tablets were then removed, dusted and weighed again. The friability of the tablets were expressed as a percentage using the formula below;

$$
\text { Friability }=\frac{\text { change in tablet weight }}{\text { original tablet weight }} \times 100
$$

\section{iv. Preparation of Ibuprofen Standard Calibration Curve}

The standard concentration was prepared by dissolving $50 \mathrm{mg}$ of Ibuprofen in $50 \mathrm{~mL}$ of $95 \%$ ethanol. This stock concentration was serially diluted appropriately using $0.1 \mathrm{~N} \mathrm{HCl}$. The drug was assayed with a spectrophotometer (U2100 PC Shanghai, China) and a standard curve of absorbance versus concentration was determined.

v. The in vitro Drug Release Study of Ibuprofen Sustained Release Tablet

The in vitro dissolution study for the tablets was carried out using the USP basket method at $50 \mathrm{rpm}$ (revolutions per minute) in a $900 \mathrm{~mL}$ dissolution medium containing $0.1 \mathrm{NHCl}$ maintained at $37 \pm 0.5$. A $10 \mathrm{~mL}$ aliquot were withdrawn and replaced with an equivalent $10 \mathrm{~mL}$ of the fresh dissolution medium. The withdrawn aliquot was filtered through a Whatman filter paper, and assayed using the UV Spectrophotometer (U2100 PC Shanghai, China). The assay was done at a wavelength of $264 \mathrm{~nm}$. 


\section{vi. Tablet Content Uniformity}

Three tablets from each batch were weighed and crushed. The powder was mixed with $20 \mathrm{~mL}$ of chloroform for 15 minutes and filtered. The residue was then washed with three $10 \mathrm{~mL}$ of chloroform and the combined filtrate was gently evaporated to dryness. The residue from the filtrate was dissolved in $50 \mathrm{~mL}$ of methanol (95\%). This solution of the residue in methanol was titrated using $0.1 \mathrm{M}$ sodium hydroxide solution, and an indicator, phenolphthalein. The content of ibuprofen was calculated with each milliliter of $0.1 \mathrm{M}$ sodium hydroxide equivalent to $0.02063 \mathrm{~g}$ of Ibuprofen.

\section{ili. Results and Discussion}

\section{a) Results}

\section{i. Properties of Gums}

The leaves of Sida acuta yielded a $3.75 \%$ gum

and is used at a concentration of $20 \%$ as a matrix former

Table 2: Properties of Guar Gum and Sida acuta Gum

\begin{tabular}{lcc}
\hline \multicolumn{1}{c}{ Parameters } & Guar Gum & Sida acuta \\
\hline Organoleptic properties & Off white odorless substance & Dark brown with a characteristic odor \\
Swelling index & $8.64 \pm 0.12$ & $8.36 \pm 0.15$ \\
$\mathrm{pH}$ & $6.06 \pm 0.10$ & $5.88 \pm 0.21$ \\
Water absorption index & $1.28 \pm 0.13$ & $1.26 \pm 0.17$ \\
Solubility & & \\
$\quad$ In water & Soluble to form mucilage & Slightly soluble \\
In ethanol & Insoluble & Insoluble \\
In acetone & Insoluble & Insoluble \\
\hline
\end{tabular}

Table 3: Confirmatory Tests of Gum

\begin{tabular}{|c|c|c|}
\hline Test & Observation & Inference \\
\hline Ruthenium Test: & & \\
\hline $\begin{array}{l}\text { Small quantity of dried gum powder mounted on a slide with } \\
\text { ruthenium red solution and observed under a microscope } \\
\text { Molisch test: }\end{array}$ & Pink color develops in both samples & Gum present \\
\hline $\begin{array}{l}0.1 \mathrm{~g} \text { of dried gum powder }+ \text { Molisch's reagent }+ \text { conc. } \mathrm{H}_{2} \mathrm{SO}_{4} \\
\text { on the side of the test tube }\end{array}$ & $\begin{array}{l}\text { Violet color observed at the function of } \\
\text { the two layers in both samples }\end{array}$ & $\begin{array}{l}\text { Carbohydrate } \\
\text { present }\end{array}$ \\
\hline
\end{tabular}

b) Micromeritics of Granules and Properties of Tablets

The densities, Carr's index, and other micromeritic parameters of both batches of granules are represented in the Table 4 below. The micromeritics of powdered materials is a measure of the flow property and indicates the potential for use in direct compression. The batch of granules formed from the gum had good flow properties with the Hausner's quotient and Carr's index being $<1.2$ and 12\% in this formulation (table 1). The yield of the gum from the leaves is low. The Sida acuta gum is a dark brown gum with a characteristic smell. On standing in an aqueous medium, it gave a swelling power of about $8 \%$, and the dispersed gum in the aqueous medium is slightly acidic. Other physicochemical properties of the gum are given in Table 2. The Ruthenium and Molisch test carried out on Sida acuta gum gave results found in Table 3. The results confirmed that what was obtained after preparation from the leaves is the hydrocolloid. the two layers in both samples

respectively. This means granules formed from the gum can be compressed without addition of anti-adherents as excipients. The tablets formed has a friability of less than $1 \%$ and a crushing strength of $5 \mathrm{Kgf}$, as seen in Table 5. The release kinetics and mechanism of the drug is seen in Table 6 and Figure 2. It shows that the tablets using Sida acuta gum released more than $95 \%$ of the drug over the 8 hour period of the study, and followed a zero order release kinetics

Table 4: Micromeritics and Flow Properties of Granules

\begin{tabular}{ccccccccc}
\hline $\begin{array}{c}\text { Batch/ } \\
\text { parameter }\end{array}$ & $\begin{array}{c}\text { Bulk density } \\
(\mathrm{g} / \mathrm{ml})\end{array}$ & $\begin{array}{c}\text { Tapped } \\
\text { density } \\
(\mathrm{g} / \mathrm{ml})\end{array}$ & $\begin{array}{c}\text { Flow rate } \\
(\mathrm{g} / \mathrm{s})\end{array}$ & $\begin{array}{c}\text { Carr's index } \\
(\%)\end{array}$ & $\begin{array}{c}\text { Hausner's } \\
\text { ratio }\end{array}$ & $\begin{array}{c}\text { Angle of } \\
\text { repose } \\
(\boldsymbol{(})\end{array}$ & $\begin{array}{c}\text { Granule } \\
\text { porosity }(\%)\end{array}$ & $\begin{array}{c}\text { True density } \\
(\mathrm{g} / \mathrm{ml})\end{array}$ \\
\hline $\mathrm{G} 1$ & $0.31 \pm 0.00$ & $0.35 \pm 0.01$ & $5.19 \pm 0.00$ & $11.43 \pm 0.02$ & $1.13 \pm 0.01$ & 33.69 & $74.60 \pm 0.38$ & $1.22 \pm 0.00$ \\
$\mathrm{G} 2$ & $0.30 \pm 0.01$ & $0.34 \pm 0.00$ & $5.60 \pm 0.00$ & $11.76 \pm 0.01$ & $1.13 \pm 0.01$ & 31.29 & $75.61 \pm 0.02$ & $1.23 \pm 0.00$ \\
\hline
\end{tabular}

Key: G1 = Granules containing guar gum

G2 $=$ Granules containing Sida acuta gum 
Table 5: Physical Properties of Ibuprofen Sustained Release Tablet

\begin{tabular}{ccccccc}
\hline $\begin{array}{c}\text { Batch } \\
\text { /Parameters }\end{array}$ & $\begin{array}{c}\text { Weight } \\
\text { uniformity } \\
(\mathrm{g})\end{array}$ & $\begin{array}{c}\text { Hardness } \\
(\mathrm{Kgf})\end{array}$ & $\begin{array}{c}\text { Diameter } \\
(\mathrm{mm})\end{array}$ & $\begin{array}{c}\text { Thickness } \\
(\mathrm{mm})\end{array}$ & $\begin{array}{c}\text { Friability } \\
(\%)\end{array}$ & $\begin{array}{c}\text { Content uniformity } \\
(\%)\end{array}$ \\
\hline $\mathrm{G} 1$ & $0.40 \pm 0.02$ & $5.00 \pm 0.01$ & $12.61 \pm 0.00$ & $3.26 \pm 0.01$ & $0.99 \pm 0.00$ & $105 \pm 1.00$ \\
G2 & $0.41 \pm 0.02$ & $5.05 \pm 0.01$ & $12.61 \pm 0.01$ & $3.27 \pm 0.01$ & $0.84 \pm 0.01$ & $103 \pm 2.00$ \\
\hline
\end{tabular}

Key: G1 Ibuprofen tablets containing guar gum

G2 Ibuprofen tablets containing Sida acuta gum

Table 6: Release Kinetics of Ibuprofen Tablets

\begin{tabular}{ccccccc}
\hline Batches & Zero Order $\left(R^{2}\right)$ & First Order $\left(R^{2}\right)$ & Higuchi $\left(R^{2}\right)$ & $\begin{array}{c}\text { Korsemeyer/Peppas } \\
\left(R^{2}\right)\end{array}$ & $n$ (diffusion coefficient) & $\begin{array}{c}t_{50} \\
h\end{array}$ \\
\hline G1 & 0.9961 & 0.8739 & 0.9582 & 0.9225 & 0.0230 & 1.90 \\
G2 & 0.9661 & 0.8692 & 0.953 & 0.9117 & 0.0110 & 1.90 \\
\hline
\end{tabular}

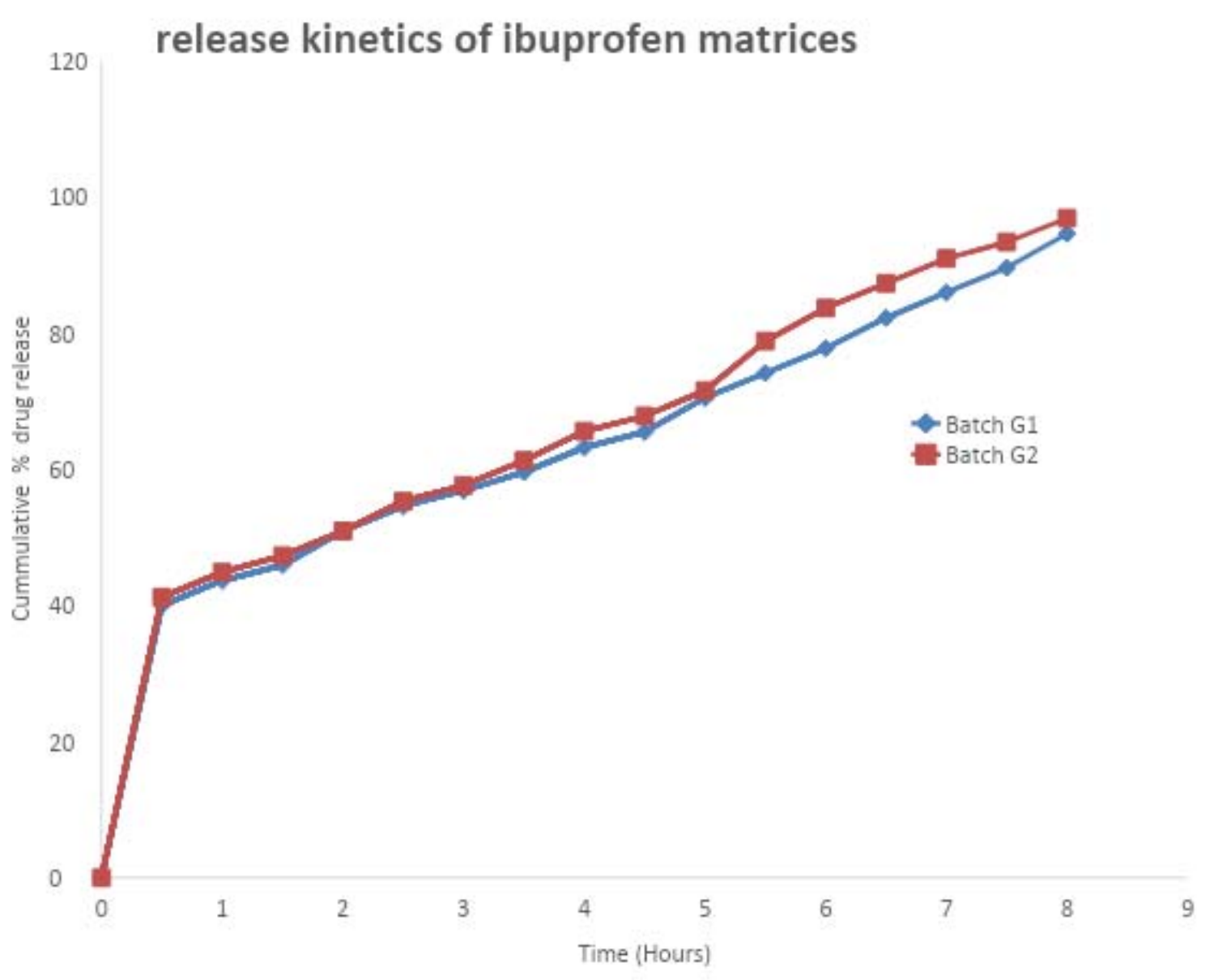

Key: G1 is tablet matrix with guar gum

G2 is tablet matrix with Sida acuta gum

Fig. 2: Release profile of Ibuprofen matrices using natural gums 


\section{Discussion}

The yield of the Sida acuta gum from the leaves of the plant is very low as compared to other gums from seeds or exudates from the stem ${ }^{4,8}$. The result seen from the Ruthenium and Molisch tests for the Sida acuta gum is same for guar, indicating confirmation of the obtained gum. The $\mathrm{pH}$ of natural polymers is a useful parameter in determining their suitability for pharmaceutical formulations. This is because the solubility and stability of active ingredients are a function of the $\mathrm{pH}$ which can be influenced by an excipient's $\mathrm{pH}$. Sida acuta being 5.88 in $\mathrm{pH}$ is weakly acidic (Table 2) while that may make the gum not suitable for use in drug formulations that might stay longer in the buccal cavity because of a possible mucosa irritation. It can, however, be useful as uncoated tablet matrix without gastric irritation ${ }^{9}$.

\section{a) Swelling index and Hydration capacity}

The swelling index of the Sida acuta gum is relatively high with a value of $8.36 \%$ although lesser than that of guar gum. The degree of swelling of a gum reveals its capacity of its individual particles to absorb water molecules and increase in size on hydration. The swelling index value of natural gums together with their simplicity and cheap production process has been reported to be reasons for their suitability for use as release modifying polymers, one way guar gum is used ${ }^{10,11}$. For the flow properties, Guar gum has been reported to have a good flow ${ }^{12}$. There is no statistical difference between the flow of the granules of both gums when tested at $p \leq 0.05$. It means that granules formed from both gums can be directly compressed without anti-adherents as excipients.

\section{b) Mechanical properties of Tablets}

The mechanical properties of the tablets show no statistically significant difference (at $p \leq 0.05$ ) for both gums in the crushing strength, friability, and tensile strength, hence on the basis of obtaining tablets with satisfactory friability and crushing strength, any of the gum could be used interchangeably. However a more sensitive parameter to determine the mechanical strength of tablets, the crushing strength friability ratio (CSFR), reveals that tablets with Sida acuta gum as matrix-former were mechanically stronger (CSFR value of 6.01) than those of guar gum (CSFR is at 5.05).

\section{c) Dissolution studies and Release kinetics}

The release kinetics of the drug is seen in Figure 2. It shows that both gums sustained the release of the drug over a period of 8 hours giving a cumulative percentage of release to be almost $100 \%$ (specifically 96\% for Sida acuta but $94 \%$ for Guar). At the 6h, $77 \%$ and $83 \%$ of drug was released from tablet batches of G1 and G2 respectively. Similar release kinetics was reported by Jaleh et al., (2006) for natural gums such as guar gum ${ }^{12}$. Thus, both gums qualify as excipients for sustained release. Drug release from a tablet matrix involves concurrent penetration of matrix by the surrounding dissolution medium, drug dissolution and drug leak out through the interstitial channels within the matrix. The interplay of these three processes predicts the drug release kinetics and is usually influenced by the physicochemical properties of the drug and the polymer ${ }^{13,14}$. It is worthy to note that while $t_{50}$ (that is the time for $50 \%$ of the drug release) for batches of tablets of both gums was the same (1.9 h), after $5 \mathrm{~h}$, batch of tablet with Sida acuta released higher percentage of the active ingredient and maintained it until the 8th $\mathrm{h}$ when it returned to the rate of release of the tablet with guar gum. This observation may be explained with the inter particulate arrangement of the gum when well hydrated in an aqueous medium. The higher swelling index value of guar gum whose gel mass retarded the drug release in the matrix core from the $5^{\text {th }} \mathrm{h}$, may likely be responsible. A similar value for $t_{50}$ was reported by Eziuzo et al., (2017) ${ }^{15}$ in his kinetic studies of diclofenac matrix tablet using Sida acuta.

The data from the dissolution studies of the two batches of drug were subjected to four drug release models and correlation coefficient (the linearity of $R^{2}$ values) describes the likely release model. The two batches of tablets released their drug content following the zero order (Table 6). This means the same concentration of the drug is released with time throughout the period of the study irrespective of the amount of the drug that is left in the matrix. Thus, drug release process is constant and independent of initial concentration of drug in the drug delivery matrix ${ }^{13}$. Sustained release matrix tablets of Sida acuta and other solid dosage forms using natural gums or their blends have been reported to follow this course of drug release although a controlled release could have different concentration released at different times as intended. ${ }^{10,12,13,15}$

\section{Conclusion}

Sida acuta gum modified the release of ibuprofen over a sustained period of $8 \mathrm{~h}$, had good swelling index and favorable micromeritics that can make it qualify for polymer useful in sustained release even as a directly compressible excipient. It is equally valuable in use as a substitute for guar gum although the main challenge is in the yield. This no doubt requires further work to see how it can be improved.

\section{a) Significant statement}

This study, therefore, discovers the release modifying potential of Sida acuta hydrocolloid comparing favorably well with guar gum, a bio-polymer that can be beneficial for application in sustained release formulations. This study will help the researcher to uncover another source for tablet matrix-former from 
Sida acuta leaves that many researchers were yet to explore. However, with the low yield got, a new process on improving yield of the hydrocolloid may be investigated.

Conflict of Interest: None

\section{References Références Referencias}

1. Khar R K, Vyas S P, Ahmad F J, and Jain G K, 2013. The theory and Practice of Industrial Pharmacy. 4th Edn., CBS Publishers and Distributors, New Delhi.

2. Aulton M E and Taylor K M G, 2013. Aulton's Pharmaceutics- The Design and Manufacture of Medicine. 4th Edn., Elsevier, London

3. Bonsu M A, Ofori-Kwakye K, Kipo SL., BoakyeGyasi ME, Fosu MA, 2016. Development of oral dissolvable films of diclofenac sodium for osteoarthritis using Albizia and Khaya gums as hydrophyllic film formers. Journal of Drug Delivery. URL: https:www.hindawi.com/journals/jdd/2016/64 59280

4. Akpabio El, Ekong US, Uwah TO, Ekpa ED, Ubolum PME, Jacobs GE, et al. Formulation and evaluation of sustained release tablets using Lesianthera africana gum. Nig J Pharm Appl Sci Res 2016; 41-8. URL: https//www.nijophasr.com

5. Frederick W.A. Owusua, Boakye-Gyasi M E, Mante P K, Ekuadzi E, Ofori-Kwakyea K, Woode E, 2019. Formulation and evaluation of sustained release matrix tablets of Capparis erythrocarpos roots extract to improve patient compliance in management of arthritis. Scientific African. [Available from journal homepage: https//www. elsevier.com/locate/scia]

6. Kalu V D, Odeniyi M A, Jaiyeoba K T, 2006 Sustained Release of a Water-Soluble Drug from Directly Compressed Okra Gum Matrix Tablets East and Central African Journal of Pharmaceutical Sciences Vol. 9 (2) 2006: pp. 46-51 DOI: 10.4314/ ecajps.v9i2.9747

7. Benjumea, D M, Gómez-Betancura I C, Vásqueza J, Alzateb F, García-Silvac A, Fontenla J A, 2015. Neuropharmacological effects of the ethanolic extract of Sida acuta .Revista Brasileira de Farmacognosia 26(2): 1-7 DOI: 10.1016/j.bjp.2015. 09.011

8. Ayorinde $\mathrm{J} \mathrm{O}$, Effiong $\mathrm{D}$ and Odeniyi M A, 2018. Design and Evaluation of Oral Dissolving Films of Chlorpheramine from Native and Modified Enterolobium Cyclocarpum Gum. African Journal of Biomedical Research 21 (2), 175-182. URL: https:// ajbrui.org/ojs/index.php/ajbr/article/view/94

9. Nitesh S C, Alka T., Kiran S., Ashu M., Umakant B, 2012. Formulation and evaluation of a fast dissolving oral film of Dicyclomine as potential route of Buccal delivery. Int. Journal of Delivery and Research 4(2): 408-417. URL: https://www.ijddr.in/ drug-development/formulation-and-evaluation-offast-dissolving-oral-film-ofdicyclomine-as-potentialroute-of-buccal-delivery. php?aid $=5179$

10. Santhi K, Dhanaraj S A, Ali A N and Sherina M, 2013. Formulation and Evaluation of Nifedipine Microbeads using Guar gum as a Release modifier. International Journal of Pharmaceutical Science Reviews and Research 21(1): 270-275. URL: https://www.semanticscholar.org/paper/Formulation -and-Evaluation-of-Nifedipine-Microbeads-SanthiDhanaraj/66cf348cc520517de6988afdc3cd118bb44 f131a

11. Munday D. L, Cox P. G., 2000 Compressed xanthan and karaya gum matrices: hydration,erosion and drug release mechanisms. International Journal of Pharmaceutics 203:179-192. DOI: 10.1016/s03785173(00)00444-0

12. Jaleh Varshosaz, Nasser Tavakoli and S. Ali Eram, 2006 Use of Natural gums and cellulose derivatives in production of sustained release Metoprolol Tablets, Drug delivery,13(2): 113-119 DOI:10.1080/ 10717540500313356

13. Okunlola A and Adewusi S A (2019) Development of Theophylline microbeads using pregellatinized breadfruit starch (Artocarpus altilis) as a novel copolymer for controlled release. Advanced Pharmaceutical Bulletin 9(1): 1-9 DOI: 10.15171/ apb. 019.012

14. Wong RSH, Doudou K (2017) Effect of drug loading method and drug physicochemical properties on the materials and drug release properties of poly (ethylene oxide) hydrogels for transdermal delivery. Polymers, 9(7): 286-315. DOI : 10.3390/polym9070 286

15. Eziuzo O S and Amarauche C (2017) Formulation and Evaluation of Dclofenac matrix tablet containing a hydrophilic polymer, Sida acuta gum World Journal of Pharmaceutical Research, 6(7):36-47. DOI: 10.20959/wjpr20177-8654 